\title{
MEREIMAJINASI METODOLOGI DAN MENGATASI SAINS FIKSI: PENDEKATAN- PENDEKATAN DALAM ANTROPOLOGI TERHADAP FENOMENA MEDIASI DIGITAL ${ }^{1}$
}

\author{
Imam Ardhianto \\ Departemen Antropologi, Universitas Indonesia
}

\begin{abstract}
Abstrak. Artikel ini menjabarkan perkembangan diskusi dalam disiplin antropologi mengenai fenomena sosial yang dimediasi oleh teknologi digital dan tinjauan kritis terhadap studi-studi tentang fenomena tersebut. Dalam konteks perkembangan antropologi di Indonesia, tulisan ini bertujuan memberikan pengantar dalam menggunakan pendekatan etnografi untuk berbagai gejala sosial budaya yang berkaitan dengan teknologi media digital atau yang muncul melalui aparatus teknologi tersebut. Tulisan ini akan diawali dengan paparan mengenai kajian-kajian etnografi terhadap teknologi media dan kesinambungannya dengan kajian-kajian mengenai media secara umum dalam disiplin antropologi. Paparan selanjutnya akan mengelaborasi pembagian kajiankajian antropologi mengenai media digital berdasarkan konsep yang mereka problematisasi: kajian yang mengartikulasikan konsep-konsep mapan dalam disiplin antropologi dan yang mengetengahkan konsep-konsep baru yang dimunculkan oleh mediasi teknologi digital dalam kehidupan sosial. Bagian akhir akan merefleksikan prospek pengembangan antropologi dalam mengkaji perkembangan gejala sosial budaya yang dimediasi teknologi media di Indonesia, termasuk pengembangan metodologinya.

Kata kunci: antropologi, etnografi, media digital, metodologi.
\end{abstract}

\begin{abstract}
This article aims to explain and critically review the recent discussions in the discipline of anthropology concerning social phenomena mediated by digital technology. By doing so, it provides for Indonesian anthropology an introduction to the use of ethnographical approach in examining various social cultural phenomena related to digital media technology or emerged through that technological apparatus. This article will begin with an exposition about ethnographic studies concerning media technology and their theoretical link to broader studies of media in the discipline of anthropology. Moreover, The following exposition will elaborate the categorization of anthropological studies of digital media based on the concepts that they problematize: studies that articulate some established concepts in anthropology and that explore new concepts emerged from the mediation of digital technology in social life. The last part of this article discusses the prospect of developing anthropological methodology for studying technologically mediated social cultural phenomena in Indonesia.
\end{abstract}

Keywords: anthropology, digital media, ethnography, methodology.

Correspondence author: Imam Ardhianto, imamardhianto@ui.ac.id, Indonesia

${ }^{1}$ Draf awal dari tulisan ini telah dipresentasikan dalam seminar nasional bertajuk "Cyber Culture and Society: Tantangan dan Peluang Ilmu Antropologi Menghadapi Era Disrupsi" yang diadakan di VIP Serbaguna Universitas Negeri Medan (Unimed), Medan, 26 November 2019. 


\section{Pengantar}

Tulisan ini adalah sebuah usaha untuk memperjelas posisi antropologi, setidaknya untuk khalayak akademisi di Indonesia, dalam melihat kemunculan teknologi media digital dan hubungan timbal baliknya dengan transformasi sosial, budaya, dan politik. Teknologi ini telah menyita begitu banyak perhatian di khalayak akademisi dan publik, hal mana tercermin dalam maraknya istilah-istilah yang berkaitan, seperti masyarakat digital, teknologi 4.0, revolusi internet, disrupsi, dan inovasi. Beberapa komentar yang kerap muncul di kalangan mahasiswa, dan tidak sedikit juga di antara kolega sesama antropolog, adalah bayangan akan patahan atau revolusi bentuk-bentuk sosial yang dialami manusia saat ini. Sering kali muncul ketakutan dan kegamangan metodologis di kalangan antropolog atau ilmuwan sosial dalam melihat penggunaan teknologi media digital. Beberapa pertanyaan pun muncul. Di antaranya, apakah antropologi atau ilmu sosial memiliki kerangka konsep dan metodologi yang memadai untuk membahas gejala tersebut? Bukankah antropologi mengasumsikan sebuah penelitian harus dilakukan dengan tinggal dalam waktu lama di suatu tempat dengan tujuan mengalami kehidupan sosial sebagai pengamatpartisipan (partisipant-observer)? Atau secara anekdotal, sering kali kita dengar komentar dari kolega yang lebih senior dalam sebuah sidang sarjana ataupun pascasarjana: "Lantas di mana etnografinya kalau kita hanya mengamati layar komputer dan gawai?"

Perlu diketahui, kegamangan dan kecemasan berkenaan metodologi di atas bukanlah sesuatu yang khas terjadi di kalangan akademisi ilmu sosial Indonesia. Hal tersebut berlangsung di berbagai tempat, bahkan pada kalangan akademisi di negara tempat teknologi digital pertama kali berkembang. Tidak heran, banyak kajian yang mengulas gejala-gejala mediasi teknologi digital seperti telepon pintar, sosial media, dan internet dengan sebuah imajinasi patahan atau keterputusan akan "realitas." Banyak karya ilmu sosial telah merespons gejala ini dengan menelurkan konsep-konsep seperti budaya siber (Cyberculture), komunitas virtual, masyarakat berjejaring (Network Society), realitas luring-daring (Offline-Online reality) (Boellstorff et al.; Castells and Himanen; Escobar et al.; Turkle "Cyberspace and Identity"; Turkle Life on the Screen: Identity in the Age of the Internet. I Can). Berkembang di awal 1990-an, kajian-kajian ini banyak meminjam terma-terma yang populer dalam narasi-narasi kebudayaan populer, terutama dari artikel sains fiksi (science fiction, sci-fi) yang terinspirasi oleh novel William Gibson berjudul Neuromancer yang diterbitkan pada tahun 1984. Pertanyaan jati diri, realitas virtual yang asing, dan representasi selalu menjadi fokus utama, dan buku tersebut pun memaparkan kemungkinan munculnya jati diri kedua, dunia yang lain, serta tentu saja, kultur dan kehidupan manusia yang berbeda. Imajinasi patahan realitas melahirkan dikotomi seperti nyata dan maya, jati diri asli dan palsu, sementara pengaruh pendekatan-pendekatan psikoanalisis melihat internet sebagai saluran bawah sadar yang melepaskan diri dari kontrol norma dan budaya. Imaji sains fiksi inilah yang nampaknya cukup mewarnai pula beberapa perdebatan yang muncul dalam ilmu sosial.

Lebih lanjut, imajinasi patahan di atas juga dipopulerkan dalam ilmu sosial oleh Manuel Castell melalui trilogi bukunya yang mengulas implikasi dari hadirnya teknologi informasi terhadap perubahan sosial dan politik (Castells and Himanen). Sebagian besar mengulas janji dan tantangan yang mengguncang konsepsi mendasar jadi manusia. Salah satunya dengan gagasan bahwa munculnya internet mampu mengguncang institusi otoritas politik, ekonomi, dan pengetahuan. Teknologi 
informasi, menurut Castell, berperan dalam perubahan modus produksi ekonomi, pengalaman individu, dan juga memudarnya institusi-institusi politik yang lama menuju pada masyarakat berjejaring (Network Societies). Masyarakat berjejaring bukan hanya menunjukkan morfologi sosial yang mencirikan hilangnya keajekan struktur sosial dalam bentuknya yang spesifik, akan tetapi, dalam bahasa Castell, masyarakat berjejaring adalah masyarakat yang mengorganisasikan struktur sosial dan aktivitasnya melalui jaringan elektronik.

Tanpa mengesampingkan bahwa pada kasus tertentu hal-hal di atas memang terjadi, pantaskah kita menjadikan hal-hal itu asumsi umum untuk memahami berbagai gejala yang sekarang kita alami dalam mediasi teknologi internet? Bukankah antropologi sebagai disiplin ilmu bermula dari kehendak menggali hakikat manusia melalui pusparagam imajinasi mengenai dunia? Untuk mengkritisi berbagai asumsi di atas, dengan dikotomi-dikotomi yang nampaknya terlalu dilebih-lebihkan, kita perlu kembali ke basis perdebatan dalam antropologi mengenai hubungan antara manusia, benda, dan teks. Sebelum berbicara mengenai media digital, tidak bisa tidak kita harus memutar kembali pembahasan kita ke kajian antropologi mengenai media.

\section{Kajian Media Digital dan Internet serta Posisinya dalam Antropologi Media(si)}

Antropologi semenjak pertama kali berdiri sebagai disiplin ilmu telah mengambil posisi keilmuan yang unik. Posisi paling krusial adalah sikapnya terhadap keanekaragaman kebudayaan. Dengan posisi tersebut, etnografi tidak memperlakukan asumsi-asumsi umum sebagai kerangka acuan dalam memahami gejala yang ia teliti. Sebaliknya, antropologi menempatkan teori/asumsi dari orang yang mereka teliti sebagai sebuah kerangka untuk dikomparasi dengan dan mengkritisi asumsi umum tempat antropologi tumbuh besar (dalam kasus sejarah antropologi, masyarakat Eropa/Amerika). Hal inilah yang disebut oleh Giovanni da Col dan David Graeber sebagai teori etnografis ( $\mathrm{Col}$ and Graeber). Alih-alih meminjam konsep-konsep yang lahir dari perdebatan filsafat Kontinental ataupun Anglosaxon dan Cultural Studies sebagai rujukan teori yang diafirmasi dan diperdebatkan - semisal Deleuze, Foucault, Alain Badiou-teori etnografis membawa konsep-konsep yang diperoleh dari masyarakat yang mereka teliti sebagai bahan perdebatan dan bahan untuk mengkritisi asumsi-asumsi besar bangunan filosofis ataupun opini publik yang berkembang di masyarakatnya. Tanpa romantisasi dan eksotisasi tempat dan kelompok yang ditelitinya, kajian etnografi memiliki potensi besar untuk merekonseptualisasi hegemoni konsep-konsep ilmu sosial Barat yang sering kali dipengaruhi oleh bias etnosentris, baik bias Barat maupun bias kelas sosial. Dengan konsepsi tersebut, bagaimanakah cara pandang teori etnografis ini dapat kita ejawantahkan dalam kerja penelitian antropologi internet dan teknologi media?

Teori-teori antropologi yang khusus membahas kemunculan teknologi media dan kaitannya dengan keragaman budaya banyak dipersepsikan sebagai sub-kajian baru, meskipun dari segi konseptual dan analitik, kajian mengenai hubungan manusia dengan medium/material di luar tubuhnya sudah setua antropologi itu sendiri. Jika kita menempatkan media sebagai perantara, manifestasi, ekspresi, ataupun penyebab material dari proses sosial suatu masyarakat, maka kajian antropologi atas media bukanlah satu hal yang baru. Durkheim, meski dengan bingkai analisis yang tidak eksplisit, sebenarnya mengedepankan bagaimana benda-benda dan citra 
memproyeksikan dan meregulasi bentuk-bentuk sosial, terutama dalam kajiannya mengenai totem dan emblem.

Hal serupa juga sudah bisa kita baca dari beragam kasus yang dielaborasi Marcel Mauss ataupun antropolog-antropolog lainnya yang membahas perputaran benda yang menandai lalu lalang informasi dan perpanjangan kehadiran seseorang pada kalung, manik-manik, atau sesederhana masakan yang didistribusikan dalam rantai pertukaran. Elaborasi Alfred Gell, yang berangkat dari tradisi antropologi Melanesia, juga membahas kompleksitas hubungan antara manusia dan benda dengan analisis berbasis semiotik, dengan melihat hubungan antara indeks (index), purwarupa (prototype), penerima (recipient), dan artis (artist). Dalam kajiannya, benda sebagai indeks bisa mensubtitusi kapasitas agensi sosial, kapasitas untuk memengaruhi dan menyebabkan elemen tertentu (Gell). Rekombinasi atas hubungan tiap unsur itulah yang biasanya menunjukkan betapa beraneka ragam hubungan manusia dan objek di luar dirinya, juga memfasilitasi upaya melihat kompleksitas jalin-kelindan manusia dan medium di luar dirinya.

Lebih lanjut lagi, berangkat dari perspektif teoretis yang berbeda, kajian mengenai manusia dan benda, serta hubungan relasional keduanya juga dieksplorasi oleh antropolog-antropolog yang dipengaruhi pendekatan linguistik dan semiotik. Perspektif yang dikembangkan oleh Webb Keane dalam mengulas ideologi semiotic (Semiotic Ideology) merupakan salah satunya. Keane mengemukakan pendekatan yang mengedepankan analisis sosial atas objek-objek material. Dalam ulasannya, ideologi semiotik dapat didefinisikan sebagai asumsi dasar mengenai apa itu benda dan bagaimana mereka berfungsi di dunia. Hal tersebut memengaruhi apa yang dianggap penting dalam proses penandaan dan intensi di baliknya dalam suatu masyarakat, kekuatan-kekuatan apa yang ada di balik proses penandaan tersebut, baik secara arbitrer atau tidak, terkait dengan sebuah objek material (Keane, 419). Sementara itu, antropolog lain seperti Illana Gherson, dipengaruhi pula oleh Webb Keane, dan juga Michael Silverstein dengan konsep ideologi-ideologi bahasanya (Language Ideologies), mengemukakan konsep ideologi-ideologi media (Media Ideologies). Ideologi-ideologi media adalah kepercayaan, sikap, dan strategi-strategi mengenai bagaimana sebuah media berfungsi. Dengan definisi ini, ideologi media juga bisa dilihat sebagai sebuah asumsi mengenai bagaimana sebuah medium memenuhi tugas-tugas komunikasi dan bagaimana seseorang bisa meyakini bagaimana sebuah medium memengaruhi atau seharusnya memengaruhi sebuah pesan (Gershon 391). Perpindahan media atau pilihan untuk tidak berpindah media dalam sebuah komunikasi mensyaratkan adanya berbagai media lain yang saling terhubung. Keterhubungan antarmedia ini disebut ekologi media. Asumsi, sikap, keyakinan (belief) mengenai satu media terkait erat dengan keberadaan media lainnya (Gershon 393).

Salah satu antropolog yang banyak mengkaji isu media, terutama radio di Jerman pada masa Perang Dingin, Dominic Boyer, mengedepankan pendekatan yang melengkapi lagi kajian-kajian mengenai media di atas. Selain membahas aspek-aspek ideologi media dan juga proses-proses perpindahan media (media switching), menurutnya antropologi juga harus mulai peka melihat transformasi platform infrastruktur informasi yang berorientasi radial, seperti logika media komunikasi klasik (radio, televisi, dan koran) menuju orientasi lateral, di mana intersubjektivitas dan keterhubungan antarsimpul terjadi karena revolusi teknologi media yang tidak lagi 
dimonopoli oleh pemerintah ataupun sektor swasta dan memungkinkan partisipasi banyak pihak atas sebuah produk teknologi media (Boyer).

Pada pendekatan radial, etnografi lebih berfokus pada proses produksi karya media seperti film, teks, radio, dan resepsi orang yang mengonsumsi produk tersebut. Banyak kajian ini membahas bagaimana negara dan sektor swasta membentuk imajinasi mengenai nasionalisme, kebudayaan, dan modernitas, sekaligus juga membahas respons audiens yang bisa jadi berbeda-beda karena konteks kultural yang berbeda. Sementara itu, dengan semakin murah dan mudahnya teknologi produksi tersebut, produksi media tidak lagi bercorak radial, sebagaimana teknologi penyiaran klasik, karena bisa dilakukan oleh siapa pun yang memiliki akses ke teknologi media. Aktoraktor ataupun kelompok tersebut dapat merespons balik produk-produk yang dihasilkan oleh teknologi komunikasi radial. Perubahan utama dari radial ke lateral bisa dilihat pada transisi dari orientasi etnografi produksi dan konsumsi, ke fokus sirkulasi, pertukaran, kontradiksi, dan juga artikulasi dari berbagai produk media. Melalui transisi fokus inilah kajian-kajian mengenai fenomena digital dielaborasi. Beberapa implikasi dari transisi tersebut bisa kita lihat pada penekanan struktur partisipasi yang berbeda jika dibandingkan pada periode struktur partisipasi media yang radial. Revolusi teknologi digital telah membuat akses ke produksi konten media lebih murah dan mudah. Terlebih lagi, ketika internet sudah menjangkau berbagai belahan dunia.

\section{Etnografi Mengenai Media Digital dan Internet}

Etnografi mengenai media digital dan, lebih khusus lagi, kaitan antara teknologi media digital (dalam hal ini komputer dan telepon pintar) sebagian besar berbicara mengenai konsep-konsep yang sudah mapan dalam kajian antropologi atau ilmu sosial secara luas. Konsep-konsep tersebut antara lain identitas, representasi budaya, komunitas, indigenitas, dan juga politik kebudayaan ( $\underline{\text { Coleman }}$. Dalam pendekatan ini, media digital dilihat lebih sebagai medium di mana kesinambungan isu-isu yang sudah dibahas dalam antropologi muncul dalam mediasi internet atas relasi sosial. Penekanannya terletak pada implikasi bentuk-bentuk kebudayaan dan otoritas kebudayaan yang muncul melalui medium ini. Selain isu-isu tersebut, banyak juga dibicarakan perdebatan mengenai hubungan antara tempat, identitas, dan medium interaksi, yang menandai kemunculan identitas-identitas dan kebudayaan nir-papan (non-place) (Augé; Gupta and Ferguson).

Salah satu kajian yang populer di kalangan antropolog berkenaan dengan persoalan tempat dan hubungannya dengan transformasi sosial yang dibawa internet adalah Daniel Miller. Miller-lah yang pertama kali mengembangkan program pascasarjana khusus di University College of London (UCL) dengan peminatan Digital Anthropology. Ia pun sudah lama mengetnografikan internet, sejak monografi pertamanya yang cukup berpengaruh, Internet: An Ethnographic Approach, yang membahas bagaimana orang-orang di Trinidad dan komunitas diasporanya menjalin tali rasa sosial melalui medium-medium seperti internet (Miller and Slater). Sejak tahun 2000, ia mengembangkan berbagai kajian, khususnya tentang bagaimana Facebook dilihat sebagai sebuah situs baru penelitian. Ia pun mengembangkan kerangka analisis yang mengedepankan bagaimana teknologi tersebut bekerja dalam proses subjektivikasi dan objektivikasi seseorang dalam melihat dirinya dalam kaitannya dengan pertalian sosial dengan orang lain (Miller). Lebih jauh, ia juga mengulas bagaimana pentingnya memahami internet dalam konteks hubungan antarplatform media, yang dengan 
mengulas ihwal tersebut isu-isu sosial bisa dikemukakan, semisal dalam konteks migrasi dan rasa memiliki (belonging) (Madianou and Miller).

Di sisi lain, pendekatan-pendekatan lain yang muncul menggambarkan sudut pandang yang lebih mengedepankan konsep-konsep yang memang muncul dan berkembang dari lapangan etnografi para pengguna teknologi media. Hal ini dilatarbelakangi oleh subjek penelitian beberapa antropolog ini, yang merupakan para pengembang perangkat lunak (software) dan peretas (hacker). Istilah yang muncul bisa disebut baru, dan menariknya dapat merekonseptualisasi banyak konsep yang sudah mapan dalam antropologi. Christopher Kelty, dalam etnografinya mengenai aktivitas perangkat lunak gratis (free software) dan sumber terbuka (open source), memunculkan diskusi mengenai publik rekursif (Kelty), sebuah komunitas yang terbentuk secara rekursif melalui praktik-praktik mengutak-atik kode pemrograman sebuah sistem operasi (operating system). Dalam kajian lain, Gabriella Coleman memublikasikan etnografi mendetailnya mengenai komunitas Anonymous yang berperan besar dalam perubahan lanskap politik dan kebudayaan di Amerika Serikat. Muncul melalui forum internet dan lahir dari Geek Culture, para aktor di balik Anonymous diulas oleh Coleman dengan memosisikannya sebagai Trickster, sebuah istilah Levi Strauss dalam analisis mitos yang menggambarkan posisi agensi yang bisa melampaui struktur nilai kebudayaan dalam sebuah plot narasi. Berangkat dari gerakan perlawanan terhadap kebangkrutan ideologi politik kubu liberal Amerika, gerakan ini-melalui praktik yang terbentuk dalam webforum, dengan anonimitasnya-melawan fondasi dasar kebudayaan Amerika yang berorientasi pada kemerdekaan individual, kompetisi, tindakan tepat secara politik (Politically Correct), kultur selebritas (celebrity culture), dan pemasaran diri (self marketing). Anonimitas, dengan praktik utama yang menandai karakter artikulasi sosial kerumunan, mengejek dasar norma ruang publik di Amerika dengan Lulz, sebuah praktik membuat prank, dan juga lelucon-lelucon yang menistakan acuan moral masyarakat arus utama.

Terlepas dari banyaknya kajian yang telah lahir dalam disiplin antropologi mengenai media digital, tulisan yang menjelaskan tahapan-tahapan dan teknik-teknik pengumpulan data terkait isu tersebut belumlah banyak. Padahal, pelajaran (lesson learned) dan berbagai pengalaman dalam menggali isu ini perlulah disistematisasi menjadi panduan awal yang bisa digunakan sebagai pintu masuk dalam proses penelitian. Sebagian besar tulisan, sebagaimana dielaborasi di atas, berorientasi pada temuan-temuan konseptual yang berkaitan dengan isu-isu yang sudah cukup populer seperti diaspora, gender, eksklusi sosial, gejala keagamaan, atau isu transformasi sosial. Dalam memaparkan aspek tersebut, penulis merasakan urgensi publikasi antropologi yang menjelaskan detail-detail melakukan etnografi terhadap gejala dunia sosial yang termediasi secara digital (digitally mediated social world).

Sebelum masuk ke detail tahapan-tahapan, perlu ditekankan bahwa etnografi sebagai sebuah pendekatan memiliki praktik yang berujung terbuka (open-ended) dan bernalar dalam praktik (logic in practice). Penekanan utama dari cara ini adalah peneliti eklektik dalam memilah dan mengombinasikan metode sesuai dengan kondisi lapangan serta kekhususan gejala/isu yang dikaji. Kajian mengenai "masyarakat rahasia" (secret society) yang hanya berbasis aplikasi percakapan (chat application) tentu akan memiliki tahapan dan teknik yang berbeda dalam membangun rapor dan menggali proses enkulturasi ketimbang komunitas yang terbuka serta lintas platform dan medium komunikasi. Metode-metode tersebut bisa jadi berasal dari metode-metode yang sudah 
lumrah dalam antropologi, seperti pengamatan terlibat (participant-observation), analisis wacana (discourse analysis), wawancara, dan observasi. Kesemua metode dan teknik tersebut dilingkupi usaha-usaha sebagaimana etnografi konvensional.

\section{Tantangan Antropologi Indonesia: Membedah Implikasi Politik dan Budaya dari Teknologi Media Digital dan Industri Pemasaran}

Berdasarkan tinjauan literatur di atas, bisa kita lihat terdapat berbagai gejala mediasi sosial berbasis digital yang memaksa antropologi sebagai sebuah disiplin memikirkan kembali teori, konsep, dan metode yang sudah mapan dalam tradisi keilmuannya. Hal yang paling kentara adalah perlunya melihat rekonfigurasi arenaarena sosial, mempertimbangkan transformasi dari ideologi-ideologi mengenai media dan praktiknya, kontinuitas dan transformasi bentuk-bentuk kultural, dan pembentukan morfologi sosial baru yang tidak lagi bisa berfokus pada paradigma kelompok untuk menuju pada paradigma jejaring. Pendekatan ini bukanlah hal yang baru. Di antropologi kajian-kajian mengenai jaringan sosial dan peran materi dalam memediasi dan secara timbal balik membentuk praktik dan ideologi sudah banyak dilakukan.

Pendekatan terhadap dimensi jejaring itu pun muncul dalam kajian-kajian mengenai politik, patronase, serta hubungan-hubungan pertemanan seperti yang sudah ditulis oleh Jeremy Boissevain dan Clyde Mitchel (Boissevain; Mitchell). Di Indonesia, sebenarnya sudah banyak juga paradigma seperti ini dikembangkan dan dikaitkan dengan situasi kontemporer. Misalnya, berbagai karya Agusyanto, baik dalam publikasi ilmiah ataupun tulisan-tulisan semi populernya (Agusyanto). Dalam diskursus etnografi, pengaruh dari model pemikir Prancis Bruno Latour juga berperan dalam melihat gejala, objek, dan subjek sebagai konsekuensi dari jejaring aktor yang meliputi pula benda material (Latour). Meskipun demikian, belum ada publikasi ilmiah dan elaborasi metodologi yang lebih khusus membahas secara mendalam hubungan timbal balik model sosial jejaring dengan hadirnya teknologi. Padahal, melihat perkembangan politik, sosial, dan kebudayaan di Indonesia, tidak bisa dimungkiri hadirnya praktikpraktik baru dalam ekspresi diri komunitas yang bercirikan sepintas lalu (ephemeral) dan cair, di mana tiap-tiap individu dan kelompok selalu berartikulasi.

Perkembangan lainnya adalah munculnya kesinambungan narasi dan idiom kultural lama serta perjumpaannya dengan yang baru, sehingga narasi lama menguat bahkan terkristalisasi. Hal ini amat kentara dalam konteks Indonesia semenjak Pemilihan Presiden (Pilpres) 2014, ketika narasi-narasi kuat era Orde Baru mengenai komunisme, separatisme, dan sejarah panjang rasisme sejak era kolonial menjadi sumber daya politik dalam memobilisasi dan membangun konstituen. Di titik inilah, politik Orde Baru dengan warisan norma, narasi, dan ide politiknya bersinggungan dengan perpanjangan dan perluasan dunia pemasaran (marketing) dalam konteks publik dan politik. Sudah terdapat banyak kajian yang membahas bagaimana pemasaran telah memengaruhi proses produksi, reproduksi, dan transformasi kebudayaan terutama di era mediasi teknologi digital. Salah satunya dengan pembentukan komunitaskomunitas konsumen semenjak kehadiran teknologi media digital. Komunitas motor, penggemar pesohor, dan tentu berbagai komunitas lain yang membentuk dan terbentuk dari industri pemasaran mewarnai ruang publik kita. Identitas tidak hanya berkait dengan kelas atau etnik, akan tetapi dengan proses-proses konsumsi komoditas. Kebudayaan pemasaran, yang memengaruhi ruang publik di Indonesia telah 
menghasilkan suatu kecenderungan pembentukan subjek yang berpusat pada diri (selfcentred), kompetitif, dan cenderung terobsesi dengan pemasaran-diri (self-marketing). Dalam hal ini, presiden dan tokoh politik pun tidak bisa lepas dari mekanisme ini. Dengan ini pula amplifikasi narasi lama menguat dan mampu membentuk polarisasi dalam lanskap politik di Indonesia. Narasi lain yang mampu bergerak dalam logika pembentukan komunitas seperti ini bersinggungan dengan afinitas kelompok keagamaan revivalis Islam dan media publik. Hal ini bisa dilihat dalam berbagai konteks perkembangan gerakan Islam, seperti dalam penelitian penulis mengenai \#IndonesiatanpaJIL yang mungkin menguat kembali melalui "Gerakan 212" (Ardhianto "Contemporary Islamic Movement, Popular Culture and Public Sphere in Indonesia: The\# Indonesiatanpajil Movement"; Ardhianto "Kontra Publik Keagamaan Dalam Media Baru: Islam, Kebudayaan Populer, Dan Media Sosial Pada Gerakan\# Indonesiatanpajil"). Meskipun demikian, terlepas dari pengaruh pemasaran melalui mediasi teknologi digital dalam lanskap politik elektoral dan kebudayaan (misalnya, dalam mendorong pemutusan basis-basis sosial seperti keluarga sebagai akibat polarisasi politik), media digital dan teknologi pemasaran tersebut juga mampu membuka ruang untuk ekspresi subaltern seperti gerakan adat, etnisitas, gerakan muda, dan juga gerakan masyarakat sipil. Selain itu, medium ini-dengan logika mobilisasi narasi dan pembentukan komunitas - juga menjadi alternatif ruang sosial baru bagi ekspresi yang liyan dalam orientasi seksualitas dan gender heteronormatif.

Untuk merespons implikasi dari perkembangan di atas, sekali lagi, disiplin ilmu antropologi di Indonesia harus merekonseptualisasi konsep-konsep yang mulai tidak operasional, seperti kebudayaan yang selalu dikaitkan dengan wilayah tempatan dan seakan memiliki batas-batas yang ketat. Antropologi perlu melihat kebudayaan sebagai konsekuensi dari artikulasi dan ekspresi "penolakan kultural" (cultural refusal) (Graeber). Dengan pendekatan tersebut, para antropolog juga harus mengembangkan metodologi etnografi digital yang mampu menjelaskan basis unit analisis yang operasional dalam kondisi kontemporer (rekombinasi analisis data statistik dan visual dengan proses etnografi konvensional). Selain itu, disiplin antropologi harus juga melakukan kerja lintas disiplin, terutama dengan kajian-kajian big data, psikologi, filologi, analisis teks, kajian-kajian visual (visual studies) untuk memperkaya kajian mendalam mengenai proses-proses perubahan tersebut. Terakhir, para antropolog dan ilmuwan sosial pada umumnya juga perlu bekerja sama (engage) dengan penelitian sektor swasta (riset pemasaran atau marketing research dan konsultan politik atau politic consultant) dan negara dengan tujuan menciptakan metodologi yang peka dan sensitif terhadap implikasi etik dan problem kultural dari intervensi institusi-institusi tersebut terhadap berbagai aspek kehidupan budaya dan politik.

\section{Penutup}

Bagian terakhir telah merangkum gejala-gejala yang muncul di Indonesia yang berkaitan erat dengan lahirnya mediasi teknologi digital dalam pembentukan ruang sosial dan politik di Indonesia. Selain itu, penulis juga telah mengulas bagaimana hal tersebut bisa kita kaitkan dengan perkembangan diskusi metodologi dalam disiplin antropologi pada subkajian antropologi digital ataupun antropologi secara umum di bagian sebelumnya. Beberapa catatan penting yang perlu dipelajari dari tinjauan penulis di atas adalah pentingnya memperhatikan pertemuan dari berbagai praktik dan kultur yang lahir dari komunitas berbasis teknologi digital dengan konteks-konteks analog. 
Pada pertemuan titik inilah, berbagai asumsi mengenai imajinasi teknologi digital yang biasanya berangkat dari imajinasi sains fiksi belum tentu muncul dalam berbagai kasus empiris. Menguatnya hubungan antara industri pemasaran, kampanye politik, dan peralihan politik konservatif di Indonesia menunjukkan bagaimana konteks politikekonomi yang melingkupi fenomena media sosial memengaruhi pengalamanpengalaman subjek yang terlibat dalam platform media sosial tertentu. Tema-tema lain seperti gender, gerakan adat, kaum muda, komunitas konsumen, dan gerakan keagamaan pun mengundang kita untuk merefleksikan betapa kontekstualnya kasus lapangan etnografi digital dengan berbedanya norma dan pembentukan kelompok, bentuk komunikasi, dan asumsi-asumsi mengenai hakikat media. Satu hal yang memaksa kita untuk selalu mereimajinasi metode, teknik, dan menjelaskan proses memasuki satu lapangan sosial. Sebuah praktik, yang bagaimanapun sudah dilakukan antropologi sejak dulu, akan tetapi dengan konteks sekarang tidak bisa tidak harus kita lakukan secara lebih intensif dengan pertumbuhan inovasi teknologi informasi yang berlangsung secara eksponensial.

\section{Daftar Pustaka}

Agusyanto, Ruddy. Jaringan Sosial Dalam Organisasi. RajaGrafindo Persada, 2007.

Ardhianto, Imam. "Contemporary Islamic Movement, Popular Culture and Public Sphere in Indonesia: The\# Indonesiatanpajil Movement." Archipel. Études interdisciplinaires sur le monde insulindien, no. 95, 2018, pp. 151-171, doi:https://doi.org/10.4000/archipel.652.

---. "Kontra Publik Keagamaan Dalam Media Baru: Islam, Kebudayaan Populer, Dan Media Sosial Pada Gerakan\# Indonesiatanpajil." Antropologi Indonesia, 2017, pp. 83-102, doi:https://doi.org/10.7454/ai.v37i2.8768.

Augé, Marc. Places and Non-Places. na, 1995.

Boellstorff, Tom et al. Ethnography and Virtual Worlds: A Handbook of Method. Princeton University Press, 2012. https:/ / books.google.co.id/books?id=RBlYYuyshzwC.

Boissevain, Jeremy. Friends of Friends: Networks, Manipulators and Coalitions. St. Martin's Press, 1974.

Boyer, Dominic. "From Media Anthropology to the Anthropology of Mediation." The ASA handbook of social anthropology, 2012, pp. 383-392, https://profiles.rice.edu/sites/g/files/bxs3341/files/inlinefiles/Sage $\% 20$ media $\% 20$ anthropology.pdf.

Castells, Manuel and Pekka Himanen. "The Power of Identity." The Information Society and the Welfare State: The Finnish Model, Oxford Scholarship Online, 2011.

Col, Giovanni Da and David Graeber. "Foreword: The Return of Ethnographic Theory." HAU: Journal of Ethnographic Theory, vol. 1, no. 1, 2011, pp. vi-xxxv, doi:10.14318/hau1.1.001. 
Coleman, E. Gabriella. "Ethnographic Approaches to Digital Media." Annual Review of Anthropology, vol. 39, no. 1, 2010, pp. 487-505, doi:10.1146/annurev.anthro.012809.104945.

Escobar, Arturo et al. "Welcome to Cyberia: Notes on the Anthropology of Cyberculture [and Comments and Reply]." Current Anthropology, vol. 35, no. 3, 1994, pp. 211231, doi:10.1086/204266.

Gell, Alfred. Art and Agency: An Anthropological Theory. Clarendon Press, 1998.

Gershon, Ilana. "Breaking up Is Hard to Do: Media Switching and Media Ideologies." Journal of Linguistic Anthropology, vol. 20, no. 2, 2010, pp. 389-405, doi:10.1111/j.1548-1395.2010.01076.x.

Gupta, Akhil and James Ferguson. Culture, Power, Place: Explorations in Critical Anthropology. Duke University Press, 1997.

Kelty, Christopher M. Two Bits: The Cultural Significance of Free Software. Duke University Press, 2008.

Latour, Bruno. Changer De Société, Refaire De La Sociologie. La découverte, 2014.

Madianou, Mirca and Daniel Miller. "Polymedia: Towards a New Theory of Digital Media in Interpersonal Communication." International Journal of Cultural Studies, vol. 16, no. 2, 2013, pp. 169-187, doi:10.1177/1367877912452486.

Miller, Daniel. Tales from Facebook. Polity, 2011.

Miller, Daniel and Don Slater. The Internet: An Ethnographic Approach. Berg. Oxford, 2000.

Mitchell, J. Clyde. "Social Networks." Annual Review of Anthropology, vol. 3, no. 1, 1974, pp. 279-299, doi:10.1146/annurev.an.03.100174.001431.

Turkle, Sherry. "Cyberspace and Identity." Contemporary Sociology, vol. 28, no. 6, 1999, pp. 643-648, JSTOR, doi:10.2307/2655534.

---. Life on the Screen: Identity in the Age of the Internet. I Can. 1995. 